\title{
A Novel, Abundant Sodium Channel Expressed in Neurons and Glia
}

\author{
Kristin L. Schaller, ${ }^{1}$ Donna M. Krzemien, ${ }^{1}$ Paul J. Yarowsky, ${ }^{2}$ Bruce K. Krueger, ${ }^{3}$ and John H. Caldwell ${ }^{1}$ \\ ${ }^{1}$ Departments of Cellular and Structural Biology and Physiology, University of Colorado Health Sciences Center, \\ Denver, Colorado 80262 and Departments of ${ }^{2}$ Pharmacology and Experimental Therapeutics and ${ }^{3}$ Physiology, \\ University of Maryland School of Medicine, Baltimore, Maryland 21201
}

\begin{abstract}
A novel, voltage-gated sodium channel cDNA, designated $\mathrm{NaCh6}$, has been isolated from the rat central and peripheral nervous systems. RNase protection assays showed that $\mathrm{NaCh} 6$ is highly expressed in the brain, and $\mathrm{NaCh} 6$ mRNA is as abundant or more abundant than the mRNAs for previously identified rat brain sodium channels. In situ hybridization demonstrated that a wide variety of neurons express $\mathrm{NaCh} 6$, including motor neurons in the brainstem and spinal cord, cerebellar granule cells, and pyramidal and granule cells of the hippocampus. RT-PCR and/or in situ hybridization showed that astrocytes and Schwann cells express $\mathrm{NaCh} 6$. Thus, this sodium channel is broadly distributed throughout the nervous system and is shown to be expressed in both neurons and glial cells.
\end{abstract}

[Key words: sodium channels, neurons, astrocytes, Schwann cells, RNase protection, in situ hybridization]

Voltage-gated sodium channels ( $\mathrm{NaChs}$ ) supply the regenerative depolarization required for electrical signaling in neurons and muscle cells. These channels are comprised of one $\alpha$ subunit $\left(\mathrm{M}_{\mathrm{r}} \approx 250 \mathrm{kDa}\right)$ and a variable number of smaller $\beta$ subunits (see Isom et al., 1994, for review). Physiologically and pharmacologically different $\mathrm{NaChs}$ have been recognized for many years, but the molecular basis for these subtypes has only recently become apparent. These functionally distinct channels could be generated by post-translational modifications since phosphorylation (Lotan et al., 1990; Dascal and Lotan, 1991; Schreibmayer et al., 1991; Gershon et al., 1992; Li et al., 1992; West et al., 1992), glycosylation (Recio-Pinto et al., 1990), and association with $\beta$ subunits (Isom et al., 1992, 1994) have been shown to affect $\mathrm{NaCh}$ behavior. However, these subtypes can also be a consequence of gene duplication and subsequent divergence since $\mathrm{NaChs}$, like virtually all ion channels in the nervous system, are members of multigene families. Five full-length rat $\alpha$ subunit $\mathrm{NaCh}$ cDNAs have been published; however, several lines of evidence, both molecular and physinlogical, indicated that more $\mathrm{NaCh}$ cDNAs remained to be isolated and

\footnotetext{
Received Aug. 15, 1994; revised Oct. 18, 1994; accepted Nov. 16, 1994.

We thank Dr. Gail Mandel for collaboration in the initial isolation of NaCh6 partial cDNAs and for providing the NaCh6-specific oligonucleotide used to screen the rat brain library (for which we thank Dr. Terry Snutch). Dr. G. Clayton (supported by NIH NS09199) provided the sections of lesioned brain. This rescarch was supported by NRSA NS08870 (K.L.S.), NSF BNS 89-19892 (P.J.Y), NIH NS16285 and AG10686 (B.K.K.), and NIH NS26505 (J.H.C.).

Correspondence should be addressed to J. H. Caldwell, Department of Cellular and Structural Biology, University of Colorado Health Sciences Center, 4200 East 9th Avenue, Box B-111, Denver, CO 80262.

Copyright (C) 1995 Society for Neuroscience $0270-6474 / 95 / 153231-12 \$ 05.00 / 0$
}

characterized. For example, the combined signal obtained by Northern analysis with probes specific for transcripts of $\mathrm{NaChs}$ I, II, and III was less than that obtained using a generic $\mathrm{NaCh}$ probc in the retina and PNS (Bcckh ct al., 1989; Beckh, 1990). A conservative estimate, based on additional partial cDNAs (Sills et al., 1989; Gautron et al., 1992; D'Archangelo et al., 1993; K. L. Schaller, D. M. Krzemien, and J. H. Caldwell, unpublished observations), is that there are at least $10 \mathrm{NaCh}$ genes in the rat. The existence of $10 \mathrm{NaCh}$ genes creates molecular complexity that is compounded by alternative splicing of the RNA (Sarao et al., 1991; Yarowsky et al., 1991; Schaller et al., 1992; Gustafson et al., 1993; Thackeray and Ganetsky, 1994) and by post-translational processing. Thus, the discovery of molecular subtypes has surpassed our understanding of the unique roles played by these channels.

There are indications that the different $\mathrm{NaCh}$ isoforms serve specialized roles. The isoforms are differentially distributed among tissues, in different areas of the CNS and at different times during development (Beckh et al., 1989; Beckh, 1990; Kallen et al., 1990; Trimmer et al., 1990; Brysch et al., 1991; Gautron et al., 1992; Furuyama et al., 1993; Black et al., 1994a). Single ncurons and muscle cells can express morc than one $\mathrm{NaCh}$ isoform, and some isoforms are localized to different subcellular regions, for example, the soma or the axon (Wollner et al., 1988; Westenbroek et al., 1989). This segregation of isoforms could permit local regulation of electrical excitability.

An unexpected discovery was that glial cells express $\mathrm{NaChs.}$ Toxin binding and patch-clamp recording from Schwann cells and astrocytes unequivocally demonstrated the presence of NaChs (for reviews, see Barres et al., 1990; Ritchie, 1992; Sontheimer, 1994). The role of voltagc-gated $\mathrm{NaChs}$ in glial cells is not clear. There is some information about which molecular isoforms are expressed in glial cells. Gautron et al. (1992) reported a partial cDNA that they designated $\mathrm{Na}-\mathrm{G}$ and considered to be glial because both cultured Schwann cells and cultured astrocytes expressed it. Na-G mRNA abundance was low in the brain, and the Na-G channel was widely expressed in other tissues. A recent study utilizing RT-PCR showed that NaChs I, II, and III are expressed in the optic nerve (Oh et al., 1994), and since there are no neurons in the optic nerve, they concluded that these isoforms are expressed in glia. Another report showed with in situ hybridization that cultured spinal cord astrocytes express $\mathrm{NaCh}$ II, NaCh III, and Na-G but not NaCh I (Black et al., 1994b).

The full-length sequence of a sixth member $(\mathrm{NaCh} 6)$ of the family of sodium channels is reported here. We present evidence 
that mRNA for $\mathrm{NaCh} 6$ is one of the most abundant sodium channel mRNAs in the brain and that it is widely distributed in both the brain and spinal cord. Finally, NaCh6 is expressed in both neurons and glia.

\section{Materials and Methods}

RNA extraction, RT-PCR, cloning, and DNA sequence analysis. The methods used for the R'I-PCR cloning are similar to those previously used (Schaller et al., 1992). Rat tissues were removed and RNA was isolated with a single-step guanidinium thiocyanate acid-phenol chloroform extraction (Chomczynski and Sacchi, 1987). Either oligo-dT (100 ng/reaction) or random hexamer (500 ng/reaction)-primed synthesis of cDNA was done in $50 \mu \mathrm{l}$ containing $1 \mu \mathrm{g}$ total RNA, $50 \mathrm{~mm}$ Tris (pH 8.3), $75 \mathrm{~mm} \mathrm{KCl,} 3 \mathrm{~mm} \mathrm{MgCl}_{2}, 5 \mathrm{~mm}$ DTT, $500 \mu \mathrm{M}$ dNTPs, and $200 \mathrm{U}$ of Moloney murine leukemia virus reverse transcriptase (Bethesda Research Labs). After synthesis at $37^{\circ} \mathrm{C}$ for $90 \mathrm{~min}, 250-500$ $\mu \mathrm{M}$ of $5^{\prime}$ and $3^{\prime}$ PCR primers and $1 \mathrm{U}$ Taq polymerase were added, and the reaction was diluted to $100 \mu \mathrm{l}$ with sterile $\mathrm{H}_{2} \mathrm{O}$. The samples were subjected to two sets of amplification, the first set consisting of five cycles of $2 \mathrm{~min}$ at $95^{\circ} \mathrm{C}, 2 \mathrm{~min}$ at $48^{\circ} \mathrm{C}$, and $2 \mathrm{~min}$ at $72^{\circ} \mathrm{C}$, and the second set consisting of 30 cycles of $2 \mathrm{~min}$ at $95^{\circ} \mathrm{C}, 2 \mathrm{~min}$ at $58^{\circ} \mathrm{C}$, and $3 \mathrm{~min}$ at $72^{\circ} \mathrm{C}$.

The initial RT-PCR cloning was performed using a $5^{\prime}$ primer which extended from nucleotide (nt) 3835 to 3866 (nucleotide numbers refer to rat $\mathrm{NaCh}$ I described by Noda et al., 1986) with an additional $14 \mathrm{nt}$ at the $5^{\prime}$ end comprising Sph I and Hind III restriction endonuclease sites; the $3^{\prime}$ primer extended from nucleotide 4660 to 4681 with an additional $14 \mathrm{nt}$ comprising SalI and EcoRI restriction sites, giving an expected DNA amplification product of 845 base pairs (bp). An additional region (more $3^{\prime}$ and overlapping with the 845 bp piece) was obtained by RT-PCR using generic primers from nt 4434 to 4460 and nt 5617 to 5643 .

The RT-PCR cloning of the approximately $1.5 \mathrm{~kb}$ of the missing $5^{\prime}$ end was done using four sets of overlapping primers. One set of generic, degenerate primers was used to amplify a cDNA of $602 \mathrm{bp}$ (primers extended from nt 244 to 269 and $n t 824$ to 845 , each with 48 -fold degeneracy), and another set of generic, degenerate primers was used to amplify a cDNA of $710 \mathrm{bp}$ (primers extended from nt 580 to 603 and nt 1268 to 1289 , with fourfold and 256-fold degeneracy, respectively). After these amplifications, products were cloned and sequenced as described below. NaCh6-specific primers were designed to amplify cDNAs to bridge the gaps; a 191 bp cDNA was amplified using primers extending from nt 1180 to 1200 and 1345 to 1370 . For amplification of the very $5^{\prime}$ end $(387 \mathrm{nt})$, a threefold degenerate oligonucleotide extending from $-13 \mathrm{nt}$ to $+3 \mathrm{nt}$ was used with a specific oligonucleotide for NaCh6 extending from nt 353 to 373 . Each of the cDNA regions cloned by RT-PCR had an overlap of 100-250 nt with the adjacent pieces, and, when sequenced, these overlaps were identical except in the regions where the primers were known to be degenerate.

After amplification, the DNA was gel purified from a $1 \%$ agarose gel using GeneClean (Bio 101), digested with the appropriate restriction endonuclease, and ligated to either MP19 or pBluescript, also restricted with the appropriate restriction enzymes. Recombinant DNA templates were prepared by standard methods (Sambrook et al., 1989). These DNAs were sequenced with a series of internal oligonucleotide primers by the dideoxy method using Sequenase (USB) according to the manufacturer's instructions. The sequence analysis and homology comparisons were done using PCGENE (Intelligenetics).

Some of the clones had a deletion which would remove half of IIIS3 and all of IIIS4. Every clone from the transformed PC12 cell line had this deletion, and some of these clones had a short insertion (63 nt) at the deletion site. These transcripts could reflect improper splicing or a means of regulating expression of the transcript.

Library screen. An oligo-dT-primed adult rat brain library, kindly provided by Dr. T. Snutch (University of British Columbia), plated at 50,000 pfu per $150 \mathrm{~mm}$ plate $(750,000$ total $)$, was transferred to nitrocellulose filters in duplicate. An oligonucleotide probe specific for NaCh6 (oligo 6A2, see below) was 5'-end-labeled with ${ }^{32} \mathrm{P}-\gamma$-ATP using T4 Kinase (Bethesda Research Labs), and hybridized to the filters for $16 \mathrm{hr}$ at $40^{\circ} \mathrm{C}$ in $6 \times \mathrm{SSC}, 20 \mathrm{~mm} \mathrm{NaH} \mathrm{PO}_{4}, 0.4 \%$ SDS, $100 \mu \mathrm{g} / \mathrm{ml}$ yeast tRNA, and $100 \mu \mathrm{g} / \mathrm{ml}$ denatured salmon sperm DNA. The filters were washed at $40^{\circ} \mathrm{C}$ in $6 \times \mathrm{SSC}, 0.1 \% \mathrm{SDS}$, and exposed to $\mathrm{x}$-ray film. After three rounds of plaque purification, the 35 positive phage obtained were transformed into Bluescript phagemids by in vivo excision. The four longest (phagemids 19, 24, 30, and 34) were sequenced on both strands using a series of internal primers as described above.

RNase protection assay. The RNase protection assay experiments were performed essentially as described previously (Schaller et al., 1992) using the same probes for RB I, II, III, IIIa, and IIIb. The probe for NaCh6 was constructed by subcloning a portion of the original 845 nt piece (Kpnl to SalI, nt 4197-4610) into pGEM4. cRNA was prepared by in vitro transcription using either T7 or SP6 polymerase in the presence of $\alpha{ }^{-32}$ P-CTP (Amersham) as described by Promega, and $5 \times 10^{5}$ dpm of each cRNA was annealed to $50 \mu \mathrm{g}$ of total RNA in $40 \mathrm{~mm}$ PIPES (pH 6.4), $0.4 \mathrm{M} \mathrm{NaCl}, 1 \mathrm{~mm}$ EDTA, and $80 \%$ formamide for $12-16 \mathrm{hr}$ at $45^{\circ} \mathrm{C}$. The labeled probe was estimated to be at least $100-$ fold in excess of the NaCh mRNA. The unhybridized RNA probes were digested at $30^{\circ} \mathrm{C}$ with RNases $\mathrm{A}$ and $\mathrm{T} 1$, and the protected probes were analyzed on a $6 \%$ polyacrylamide, $8 \mathrm{M}$ urea gel and exposed to $\mathrm{x}$-ray film. The relative abundance of the various isoforms was analyzed by direct measurement of radioactive decay (Phospholmager, Molecular Dynamics). Controls for nonspecific hybridization consisted of (1) the sense strand for each probe and (2) the antisense probe hybridized to liver RNA or to tRNA. No signal was present in any of the controls. An aliquot $(500 \mathrm{dpm})$ of the labeled probe was loaded onto the gel to indicate the size of the unprotected probe.

Northern analysis. RNA gel electrophoresis, gel blotting, and hybridization were performed essentially according to Sambrook et al. (1989). Total RNA ( $50 \mu \mathrm{g} / \mathrm{lane}$ ) was electrophoresed through a $0.8 \%$ agarose gel containing $6 \%$ formaldehyde. The RNA was transferred to Zetaprobe membrane (Bio-Rad). Hybridizations were performed $16 \mathrm{hr}$ at $65^{\circ} \mathrm{C}$ in $6 \times \mathrm{SSC}, 5 \times$ Denhardt's, $1 \%$ SDS, $200 \mu \mathrm{g} / \mathrm{ml}$ denatured salmon sperm DNA, $100 \mu \mathrm{g} / \mathrm{ml}$ yeast tRNA, and $1 \times 10^{\circ} \mathrm{dpm} / \mathrm{ml}$ of ${ }^{32} \mathrm{P}$-labeled antisense riboprobe containing the $3^{\prime}$ UTR from phagemid 30 . The membranes were washed in $0.2 \times \mathrm{SSC}, 1 \% \mathrm{SDS}$ at $70^{\circ} \mathrm{C}$, and exposed to $\mathrm{x}$-ray film for 16-48 hr. An RNA ladder (Bethesda Research Labs) consisting of poly A transcripts ranging in size from 0.24 to $9.5 \mathrm{~kb}$ was used to size the NaCh6 transcript.

In situ hybridization and anti-GFAP immunocytochemistry. One sense and two antisense oligonucleotide probes were constructed against NaCh6 cDNA sequences: 5'-CTGCTGCAATGGCCACCTCAGCGGG3' (oligo 6S1), nt 1345-1370; 5'-TATCGATTTCGAACCGGATTTCAGAAGTCTCA-3' (oligo 6A1), nt 4062-4091; and 5'-CCCGCTGAGGTGGCCATTGCAGCAG-3' (oligo 6A2), nt 1345-1370. These sequences were specific for $\mathrm{NaCh} 6$ and were selected to show little sequence homology to other $\mathrm{NaCh}$ genes or any other sequence in the EMBL or GeneBank databases. The nucleotide identity between oligo $6 \mathrm{Al}$ and the other isoforms ranged from $30 \%$ to $53 \%$ (NaCh I, $40 \%$; $\mathrm{NaCh}$ II, 33\%; NaCh III, 53\%; SkM1, 37\%; SkM2, 30\%). The nucleotide sequence of $6 \mathrm{~A} 2$ and $6 \mathrm{~S} 1$ was not present in muscle isoforms and was $44.48 \%$ identical to brain isoforms ( $\mathrm{NaCh} \mathrm{I,} \mathrm{48 \% ;} \mathrm{NaCh}$ II and III, 44\%). In situ hybridization and immunocytochemistry experiments were performed using a modification of the procedure of Mahalik et al. (1992). Rats were transfused through the heart with $4 \%$ paraformaldehyde in PBS $(0.1 \mathrm{~m}$ phosphate buffer, $\mathrm{pH} 7.6 ; 0.9 \% \mathrm{NaCl})$ and the brains and spinal cords removed, stepped through $20 \%$ sucrose in PBS for 24 hr followed by $30 \%$ sucrose in PBS for $24 \mathrm{hr}$, and frozen at $-80^{\circ} \mathrm{C}$ until they were sectioned. Sections were laken both coronally and parasagittally $(25 \mu \mathrm{m})$ through the brain, and transversely through the spinal cord. The sections were rinsed in $1 \times$ SSC and then placed in hybridization buffer $(50 \%$ formamide, $10 \%$ dextran sulfate, $4 \times$ SSC, $0.5 \times$ Denhardt's, $5 \mathrm{~mm}$ DTT, $250 \mu \mathrm{g} / \mathrm{ml}$ denatured salmon sperm DNA, and $250 \mu \mathrm{g} / \mathrm{ml}$ yeast tRNA) containing $1.0 \times 10^{6} \mathrm{dpm}$ of ${ }^{35} \mathrm{~S}$-labeled oligonucleotide probe per $100 \mu \mathrm{l}$. The oligonucleotide probes were labeled at the $3^{\prime}$ ends using terminal transferase (Stratagene) in the presence of ${ }^{35} \mathrm{~S}$-dATP (New England Nuclear); specific activities ranged from $1 \times$ $10^{8}$ to $5 \times 10^{8}$. After hybridization at $26^{\circ} \mathrm{C}$ for $16-24 \mathrm{hr}$, the sections were washed in $1 \times \mathrm{SSC}$ at $26^{\circ} \mathrm{C}$ for $30 \mathrm{~min}$ followed by a $30 \mathrm{~min}$ wash in $0.2 \times \mathrm{SSC}$ at $45^{\circ} \mathrm{C}$, and then were either mounted onto gelatin-coated slides and allowed to air dry or processed for immunocytochemistry as follows.

The sections were briefly washed in PBS and blocked with 10\% BSA (bovine serum albumin), $0.3 \%$ Triton X-100 in PBS for $1 \mathrm{hr}$ at room temperature. The sections then were incubated in $2 \% \mathrm{BSA}, 0.3 \%$ Triton $\mathrm{X}-100$ in PBS containing a mouse monoclonal antibody (Boehringer Mannheim) against GFAP (glial fibrillary acidic protein) at $4^{\circ} \mathrm{C}$ for $16-$ $24 \mathrm{hr}$. The sections were washed in PBS and placed in $2 \%$ BSA, $0.3 \%$ Triton X-100 containing a biotinylated rat polyclonal sera (Jackson Laboratories) against mouse $\mathrm{IgG}$ for $2 \mathrm{hr}$ at room temperature. The sections 


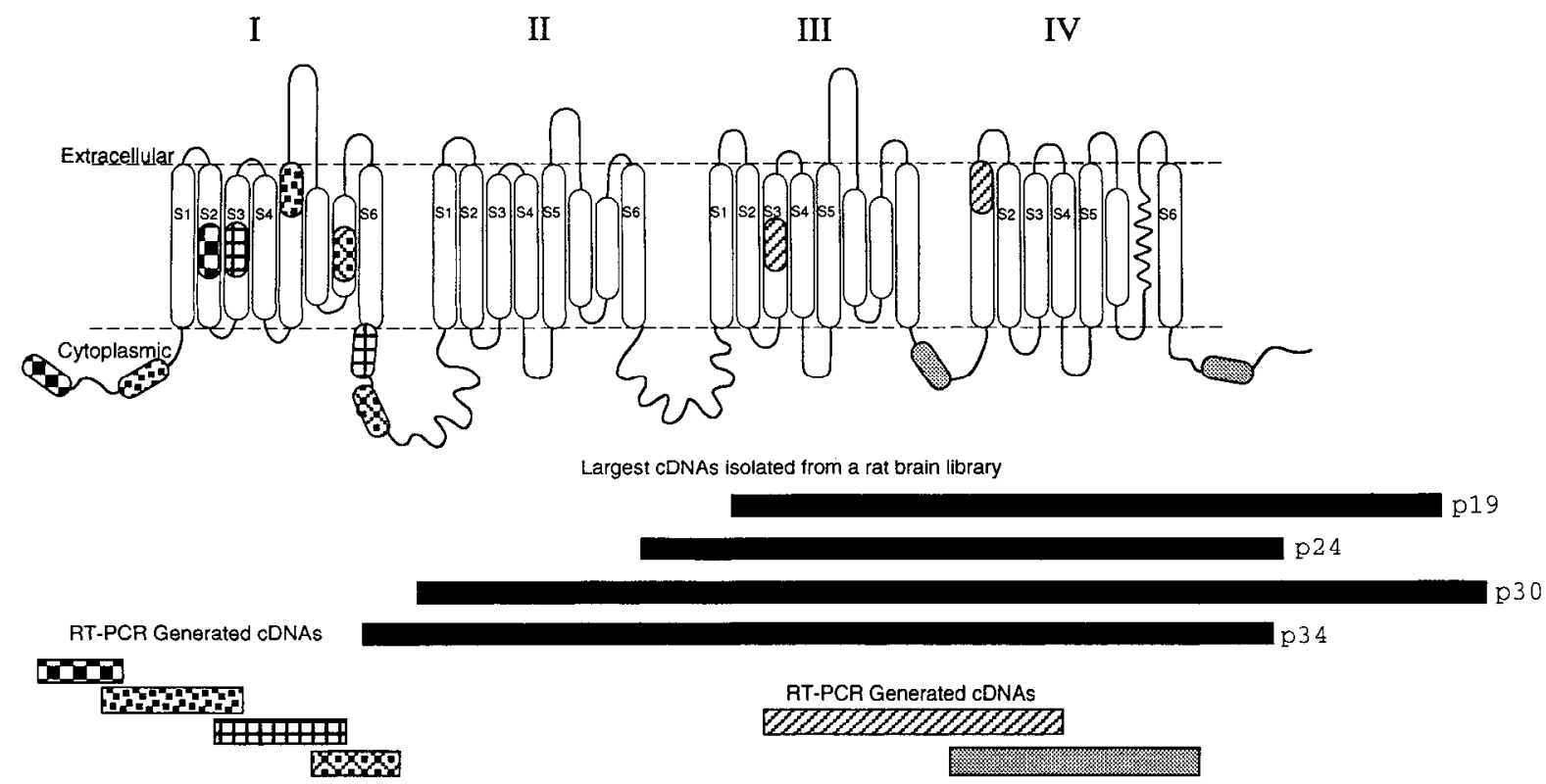

Figure 1. Cloning of rat NaCh6. Overlapping clones that provided the complete coding region and an illustration of the secondary structure of NaChs. Thirty-five cDNA clones were obtained from a brain library; the positions of the four longest clones are indicated in the figure. The longest clone was about $8 \mathrm{~kb}$. Partial cDNA clones from different regions were obtained by PCR. Pairs of ovals in the secondary structure diagram indicate the positions of the PCR primers used to generate these clones.

were again washed, then reacted with an avidin-biotin complex, and the immunoreactivity visualized with diaminobenzidine. The sections were mounted onto gelatin-coated slides and exposed to B-Max hyperfilm (Amersham) for $40-48 \mathrm{hr}$ at room temperature. Following this, the slides were dipped in Kodak NTB-2 emulsion and exposed for 1-3 weeks at $4^{\circ} \mathrm{C}$. The emulsion-dipped slides were developed in Kodak D-19 developer, fixed, counterstained with cresyl violet, dehydrated, and coverslipped. The slides were photographed using a Zeiss Axiophot microscope.

Controls used to assure specificity of the in situ hybridization experiments were a sense probe that gave no specific hybridization, and hybridization with ${ }^{35} \mathrm{~S}$-labeled antisense oligonucleotides that could be blocked by incubation with an excess (25-50-fold) of the same unlabeled oligonucleotide (see Fig. 5).

Astrocyte cultures. Primary astrocyte cultures were prepared and maintained as described by Yarowsky and Krueger (1989). Cerebral hemispheres of newborn rats were removed, placed in modified DMEM/ F12 medium with $10 \%$ fetal calf serum, cleaned of meninges, trimmed, and mechanically disrupted by vortexing. The cell suspension was then filtered, first through $80 \mu \mathrm{M}$ sterile nylon sieving cloth, then through 10 $\mu \mathrm{m}$ cloth, and plated at a density of $2-3 \times 10^{\circ}$ cells per $35 \mathrm{~mm}$ dish. An immortalized astrocyte cell line (A7) was maintained in medium RPMI 1640 containing $10 \%$ fetal bovine serum. For in situ hybridization/immunocytochemistry, both primary and immortalized astrocyte cells were grown on poly-L-lysine-coated coverslips in the appropriate medium, fixed for $10 \mathrm{~min}$ in $4 \%$ paraformaldehyde, washed in PBS, dehydrated, and frozen at $-80^{\circ} \mathrm{C}$ until used.

\section{Results}

Cloning of NaCh6 $\alpha$ subunit cDNA

Since there was evidence for additional NaChs in the CNS, PNS, and in glial cells, we isolated partial $\mathrm{NaCh}$ cDNA clones using RT-PCR with RNA isolated from a variety of rat tissues including brain, retina, and dorsal root ganglia, as well as from retrovirally transformed PC 12 cells and primary cultures of neonatal rat cortical astrocytes. We chose to use PCR primers that amplified an 845 nucleotide region from IIIS3 to IVS1 (Fig. 1) because we have successfully amplified $\mathrm{NaCh}$ cDNAs from a wide range of species with these primers. Partial cDNAs for NaCh6 were obtained from all of the sources described above. From the sequence of the PCR product, an oligonucleotide spe- cific for NaCh6 was synthesized and used to screen a rat brain oligo-dT-primed cDNA library (a gift of Dr. Terry Snutch). All of the 35 clones that were isolated contained the 845 nucleotide sequence obtained by PCR. We analyzed the four longest clones (Fig. 1). The most 5' clone (phagemid 34) was approximately 4700 nucleotides in length; it began near the $3^{\prime}$ end of IS6 and included 71 nucleotides of $3^{\prime}$ untranslated sequence (Fig. 1). Further screening of this library and the other 34 positive clones with an oligonucleotide near the $5^{\prime}$ end of p34 did not yield any clones with additional $5^{\prime}$ sequence. Screening of additional libraries was also unsuccessful.

Therefore, RT-PCR was used to amplify and clone the missing $5^{\prime}$ end of the cDNA. RNAs from neonatal rat astrocyte cultures and from adult rat brain were used with four sets of overlapping primers, some of which were generic for all NaChs and others which were specific for NaCh6 (see Materials and Methods). Multiple individual clones were sequenced for each of the primer pairs to ensure that Taq polymerase errors were excluded. Identical nucleotide sequences were obtained where adjacent PCR products overlapped (100-250 nt of overlap). This strategy yielded the full-length sequence of the coding region (1976 amino acids) with a predicted molecular weight for the protein of 225,227 daltons (Fig. 2). This cDNA has been designated rat $\mathrm{NaCh} 6$ because it is the sixth full-length rat $\mathrm{NaCh}$ sequence to be published. In addition, a neutral name is appropriate for a channel that we show below to be expressed throughout the nervous system and in both neurons and glia.

The primary amino acid sequence has the same predicted secondary structure as five published rat NaChs. There are four large membrane-spanning domains (I-IV), each with six predicted transmembrane $\alpha$ helices (S1-S6) and two highly conserved regions (SS1 and SS2) that are thought to form part of the pore. Predicted transmembrane domains and a short cytoplasmic domain critical for inactivation (interdomain III-IV) are highly conserved among the known rat $\mathrm{NaCh}$ cDNAs (Fig. 2). These regions have $74-94 \%$ amino acid identity with NaCh6 
Rat NaCh 6 Rat NaCh 1 Rat $\mathrm{NaCb} 2$ Rat NaCh Rat Sk M Rat sk Y 2

Rat NaCh 6 Rat NaCh 1 Rat NaCh Rat NaCh

$\begin{array}{llll}\text { Rat } & \text { Sk } & \text { M } & \\ \text { Rat } & \text { Sk } & \text { M } & 2\end{array}$
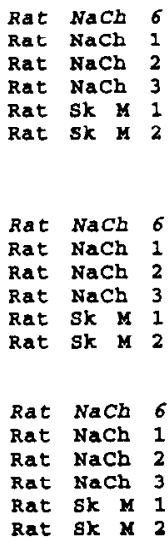

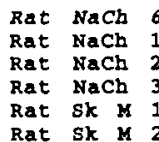

Rat NaCh 6 Rat NaCh 1 Rat NaCh 2 Rat NaCh 3 $\begin{array}{llll}\text { Rat Sk } & \mathbf{M} \\ \text { Rat } & \text { sk } & 2\end{array}$

MRRSA-RLLAPPGPDSFKPFTPESLANIERRIAESKLKK-PPKADGSHREDDEDSKPKPNSDLEAGKSLPFIYGDIPOGLVAVPLEDFDPYYLTOKTFVV MEOT - - -VLVPPGPDSFNFFTRE SLAA IERR I AEEKAKN-PKPD-- -KKD-DDENGPKPNSDLEAGKNIPFIYGDIPPEMVSEPIEDLDPYYINKKTFIV GARS - - VL VPGPDSFNFFTRESLAAI ERRIAEEKAKN-PKPD- - KKD-DDENGPKPNSDLEAGKNLPFIYGDIPPEMVSE PLEDLDPYYINKKTFIV UAOA - - L P PGDSFRFFTRE LAA IEQRIAEEKAKR-PKQE- -RKDEDDENGPKPNSDLEAGKSLPFIYGDIPPEMVSEPLEDLDPYYINKKTFIV MASSSLPNLVPPGPHCLRPFTPESLAAIEQRAVEEEARL-QRN----KQMEIEEPERKPRSDLEAGKNLPLIYGDPPPEVIGIPLEDLDPYYSDKKTFIV

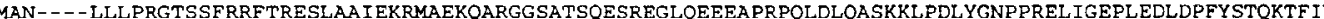

LNRGKTLFRFSATPALY ILSPFNLIRR I AIK ILIHSVF SMI IMCTILTNCVFMTFSNPPEWSKNVEYTFTGIYTFESLVKI I ARGFCIDGFTFLRDPWNW LNKGKA I FRFSATSAI Y ILTPFNPL RKIA IKILVHSLF SML IMCTILTNCVFMTMSNPPDWTKNVEYTFTG IYTFESL IK I IARGFCLEDFTFLRDPWNW LNKGKAI SRF SATSAL YILTPFNPIRKLAIKILVHSL FNVL IMCTILTNCVFMTMSNPPDWTKNVEYTFTG IYTFESL IKILARGFCLEDFTFLRNPWNW WNGAISF LNRGA LNKGKTIFRF SATNALYVLSPFHPVRRAAVKILVHSLF SMLIMCTILTNCVFMAOHDPPPWTKYVEYTFTAIYTFESLVK ILARGFCLIAFTFLRDPWNW ISI IS2

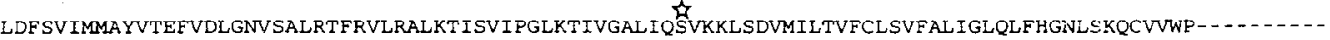
LDFTV ITEAYYTEFVDLGNVSALRTFRVLRALKT' I SVI PGLKTIVGAL IQSVKKL SDVMI LTVFCLSVFALIGLQLFMGNLRNKCVQWPP- - - - TNASLE LDFTVITFAYVTEFVNLGNVSALRTFRVLRALKTISVI PGLKTIVGAL IOSVKKLSDVMILTVFCLSVFALIGLQLFMGNLRNKCLQWPP - ...-DNSTF LDFSVIVMAYYTEFVDLGNVSALRTFRVLRALKTISVIPGLKTIVGAL IQSVKKLSDVMILTVFCLSVFALIGLQLFMGNLRNKC SQWPP- - --SDSAFE EDF SVITMAYVTEFVDLGNI SALRTFRVLRAL KTITVIPGLKT IVGAL IOSVKKL SDVMILTVFCLSVFALVGLOLFMGNLROKCVRWPPPMNDTNTTWY LDF SVIVMAYTTEFVDLGNV SALRTFRVLRALKTISVISGLKT IVGAL IOSVKKLADVMVLTVFCLSVFALIGLOLFMGNLRHKCVRNFTELNGTNGSVE

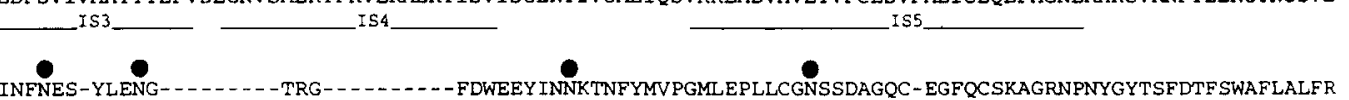

INFNES-YLENG- - - - - - TRG-- - - . - - FDWEEY INNKTNFYMVPGMLEPLLCGNSSDAGQC-EGFQCSKAGRNPNYGYTSFDTF SWAFLALFR EHSIEK-NVTTDYNGT-LVNET-------VFEFDWKSYIQDSRYHYFLEGVLDALLCGNSSDAGQCPEGYMCVKAGRNPNYGYTSFDTF SWAFLSLFR INITSFFNNSI.DWNGT - AFNRT - - - . - - - -VNMFNWDEY IEDKSHFYFLEGQNDALICGNSSDAGOCPEGY ICVKAGRNPNYGYTSFDTFSWAFLSLFR TNTTSYFNGT'MDSNGT-FVNVT - - - ....-MSTFNWKDY IADDSHFYVLDGQKDPLLCGNGSDAGQCPEGYICVKAGRNPNYGYTSFDTFSWAFLSLF GNDTWYSNDTWYGNDTWY INDTWNSOESWAGNSTFDWEAY INDEGNFYFLEGSNDALLCGNSSDAGHCPEGYECIKAGRNPNYGYT SYDTF SWAFLALFR ADGL_... . . . . - - VWNSLDV-_... - YLNDPANYLLKNGTTDVLLCGNSSDAGTCPEGYRCLKAGENPDHGYTSFDSFAWAFLALFR

LMTQDYWENLYQLTLRAAGKTYMIFFVLVIFVGSFYPVNL ILAVVAMAYEEQNQATLEEAEQKEAEFKAMLEQLKKQQEEAQAAAMATSAGTVSEDAIEE LMTODFWINL YOLTLRAAGKTYMIFFVLVIFLGSFYLINL ILAVVAMAYEEONOATLEEAEOKEAEFOOMLEQLKKOOEAAOQAAAATAS---- EHSLM LMTOWN LMTQDYWENLYQLTLRAAGKTYMIFFVLVIFLGSFYLVNLILAVVAMAYEEQNQATLEEAEQKEAEFQQMLEQLKKQQEEAQ-AVAAASA- - - - ASRDP LMTQDYWENLFQLTLRAAGKTYMIFFVVI I FLGSFYLINLILAVVAMAYAEQNEATLAEDQEKEEEFQQMLEKYKKHQEELE- ISS2_ IS6

EGEDGVGS-PRSSSELSKLSSKSAKERRNRRKKRKOKELSEGEEKGDPEKVFKSESEYGMRRKAFRLP--DNRI--GRKFSIMNQSLLSIPGSPFLSRHN REPSAAGRLSDSSSEASKLSSKSAKERRNRRKKRKQKEQSGGEEKDDDE-FHKSESEDSIRRKGFRFSIEGNRLTYEKRYSSPHOSLLSIRGSLFSPRRN SGAGGIGVFSESSSVASKLSSKSEKELKNRRKKKKOKEQAGEEEKEDA--VRKSASEDSIRKKGFOF SLEGSRLTYEKRFSSPHQSLLSIRGSLFSPRRN SGIGGLGELLESSSEASKLSSKSAKEWRNRRKKRRQREHLEGNHRADGDRFPKSESEDSVKRRSFLLSLDGNPLTGDKKLCSPHQSLESIRGSLFSPRRN SGIGGLGLLESSSEASLS TIRGVDTVSRSSLEMSPLAPVTNHERKSKRKR---- LSSGTEDGGDDRLPKSDSEDGPR-- - ALNOLSLTHGLSRTSMRP -

SKSSIFSFGDPSVRDPGSENEFADDEHSTVEESEGRRDSLFIPIRARERRSSYSGYSGYSQCSRS STS-ISPACAQREANSTVDCNGVVSLIG - - - - PGS SKSSIF SFGDPSVRDPGSENEFADDEHSTVEESEGRRDSLFIPIRARERRSSYSGYSGYSQCSRSSR-ISPACAQREANSTVDCNGVVSLIG-----PGS
SRTSLFSFRGR-AKDVGSENDFADDEHSTFEDNESRRDSLFVPRRHGERRNS----NLSQTSRSSRMLAGLPANGKMHSTVDCNGVVSLVG-GPSVPTS SRASLFNFKGR-VKDIGSENDFADDEHSTFEDNDSRRDSLFVPHRHGERRPS-----NVSQASRASRGI PTLPMNGKMHSAVDCNGVVSLVG-GPSALTS SKTSIFSFRGR-AKDVGSENDFADDEHSTFEDSESRRDGLFVPHRPGERRNS SRGSIFTFRRR---DQGSEADFADDENSTAGESESHRTSLLVPWPL--RHPSAQGQPGPGASA------PGYVLNGKRNSTVDCNGVVCFLGAGDAEATS HIGRLLLRQRLRW-- - - - KLRRKALDSFSFYGPTRLLRTEGQNQQHNERGH - KHASEELEESQRKCPPCWYKFANTFLIWECHPYWIKLKEI PVGQLLPEVI IDKPATDDNGTTTETEMRKRRSSSFHV--SMDF LEDPSQRQRAMS IASILTNTVEELEESRQRCPPCWYKFSNIFL IWDCSPYWLKVKHI PVGQLLPE---1---GTTTETEIRKRRSSSYHV--SMDLLEDPS-RQRAMSMASILTNTMEELEESRQKCPPCWYKFANMCLIWDCCKPWLKVKHV

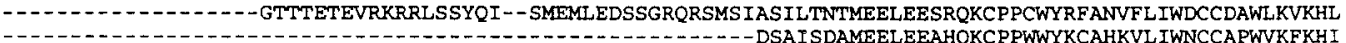
PGSYLLRPMVLDRPP--DTTTPSEEPGGPQMLTPQAPCA--DGFEEPGARORALSAVSVLTSALEELEESHRNCPPCWNRFAOHYL IWECCPLWMSIKOK

VNLIVMDPFVDLAITICIVLNTLFMAMEHHPMTPQFEHVLAVGNLVFTGIFTAEMFLKL IAMDPYYYFOEGWNIFDGFIVSLSLMELSLADVEGLSVLRS VNLVVMDPFVDLA I T ICIVLNTL FMAMEHY PMTEHFNHVLTVGNLVFTGIFTAEMFLKI IAMDPYYYFQEGWNIFDGF IVTLSLVELGLANVEGL SVLRS VNLVVMDPFVDLAITICIVLNTL FMAMEHYPMTEOFSSVLSVGNLVFTGIFTAEMFLKI IAMDPYYYFOEGWNIFDGFIVTLSLVELGLANVEGLSVLRS VNLIVMDPFVDLA ITICIVLNTLFMAMEHYPMTOOF SSVLTVGNLVFTGIFTAEMVL KI IAMDPYYYFOEGWNIFDGI IVSLSLMELGLANVEGLSVLRS IYLIVMDPFVDLG ITICIVLNTLFMAMEHY PMTEHFDNVLSVGNLVFTG IFTAEMVLKLIAMDPYEYFOOGWNIFDSFIVTLSLVELGLANVOGLSVLRS

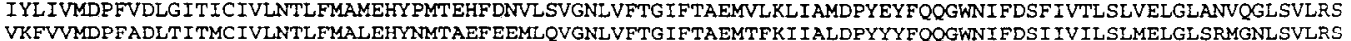
VKFVVMDPFADLT ITMC IVLNTL FMALEIYYNMTAEF EEMLQVGNLVFTGIFTAEMTFKI IALDPYYYFQQGWNIFDS I IVILSLMELGLSRMGNLSVLRS

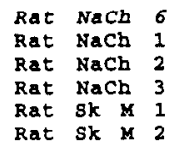

Rat $\mathrm{NaCh} 6$ Rat $\mathrm{NaCh} 1$ Rat NaCh 2 Rat NaCh 3 Rat Sk M 1

Rat $\mathrm{NaCh}$ Rat NaCh Rat NaCh Rat $\mathrm{NaCb} 3$ Rat sk is 1 Rat Sk $M$

FRLLRVFKLAKSWPTLNML IKIIGNSVGALGNLTLVLAIIVF IFAVVGMQLFGKSYKECVCK INQECKLPRWHMNDFF HSFLIVFRVLCGEWIETMWDCM FRLLRVFKLAKSWPTLNMLIKI IGNSVGALGNLTLVA I IVF I FAVVGMOLFGKSYKDCVCKI ATDCKLPRWHMNDFFHSFLIVFRVLCGEWI ETMWDCM FRLLRVFKLAKSWPTLNML. IKI I GNSVGALGNLTLVLAI IVF IFAVVGMOLFGKSYKECVCKI SNDCELPRWHMHHFF HSFLIVFRVLCGEWIETMWDCM FRLLRVF KLAKSWPTLNMLI I I I GNSVGALGNLTLVLAI IVF IFAVVGMQLEGKSYKECVCKINVDCKLPRWHMNDFFHSFLIVFRVLCGEWIETMWDCM FRLLRVFKLAKSWPTLNML IK I I GNSVGALGNL TLVLA I IV IFAVVGMOLFGKSYKECVCKI ASDCNLPRWHMNDFFHSFLIVFR ILCGEWIETMWDCM FRLLRVFKLAKSWPTLNTLIK I I GNSVGALGNLTLVLAI IVF I FAVVGMQLFGKNYSELRHR I SDSGLLPRWHMMDFFHAFL I I FR ILCGEWI ETMWDCM IIS5 IISS1_ IISS2

EVAGQAMCLIVFMMVMVIGNLVVLNLFLALLLSSFSADNLAATDDDGEMNNLQISVIRIKKGVAWTKVKVHAFMQAHF- - KQREADEVKPLDELYE- -KK EVAGQAMCLTVFMMVMI RNLVVLNLFLALLLSSFSADNLAATDDDNEMNNLQIAVDRMHKGVAYVKRKIYEF IQQSFVRKQKILDEIKPLDDLNN--RK EVAGQTMCLTVFMMVMVIGNLVVLNL,FLALLLLSSFSDNL,AATDDDNEMNNL QI AVGRMQKGIDFVKRKIREF IQKAFVRKQKALDFI KPLEDLNN- -KK EVAGQTMC I IVFML VMVIGNLVVLNLFLALLLSSFSSDNLAATDDDNEMNLQIAVGRMQKGIDFVKNKIRECERKAFFRKPKVIE---- IQEE-GN--KI

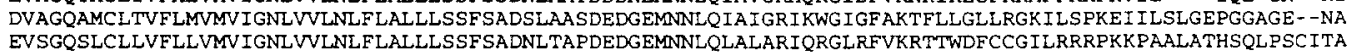

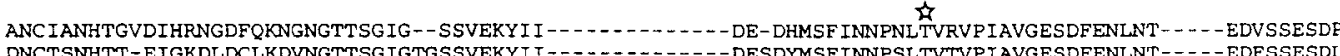
DNCTSNHTT-EIGKDLDCLKDVNGTTSGIGTGSSVEKYII--

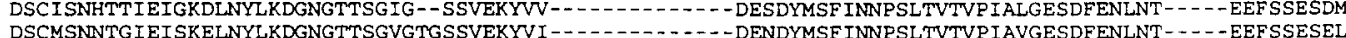
DSCMSNNTGIEISKELNYLKDGNGTTSGVGTGSSVEKYVI-- $-1 \ldots \ldots$ DENDYMSF INNPSLTVTVPIAVGESDFENLNT - - - EEFSSESEL

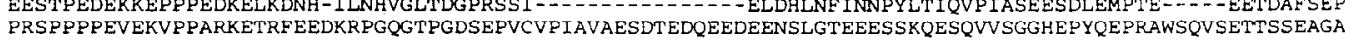

741

760

751
703 564
709 


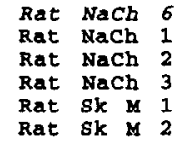

Rat NaCh 6 Rat NaCh 1 Rat Nach 2 Rat Nach 3 Rat sk M I Rat Sk $M 2$

$\begin{array}{lll}\text { Rat NaCh } & 6 \\ \text { Rat NaCh } & 1 \\ \text { Rat NaCh } & 2 \\ \text { Rat NaCh } & 3 \\ \text { Rat Sk M } & 1\end{array}$

Rat NaCh Rat Nach 1 Rat NaCh Rat NaCh Rat sk $\mathrm{a}$ Rat Sk

Rat NaCh Rat Nach Rat NaCh 3 Rat sk o Rat sk

Rat NaCh Rat NaCh Rat $\mathrm{NaCh}$ Rat $\mathrm{NaCh} 3$ Rat sk M 1 Rat sk $\mathbf{M}$

Rat NaCh Rat NaCh Rat NaCh Rat NaCh Rat $8 k$ K Rat Sk M
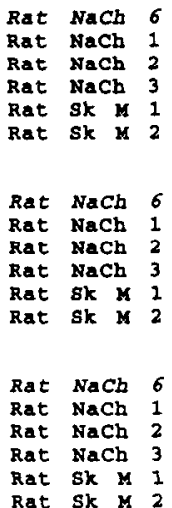

1197

122

1211

1160

1027

20 STSQADWQOEOKTEPQA.PGCGETPEDSYSEGSTADMTNTADLLEOI PDLGEDVKDPEDCFTEGCVRRCPCCMVDTTQSPGKVWWLRKTCYR IVEHSWFE

TF I IFMILLSSGALAFEDIY IEQRKT IRTILEYADKVFTY IF ILEMLLKWTTYGFVKFFTNAWCWLDFLIVAVSLVSLIANALGYSELGA IKSLRTLRAL TFIVFMILLSSGALAFEDIYIDORKTIKTMLEYADKVFTYIFILEMLLKWVAYGYOTYFTNAWCWLDFLIVDVSLVSLTANALGYSELGAIKSLRTLRAL TFIVFMILLSSGA AFEDIYIEORKT IKTML EYADKVFTY IFILEMIKWVAYGFOMYFTNAWCWT DFLIVDVSLVSLTANALGYSELGAIKSLRTLRAL TFI IFMILLSSGALAFEDIYLEERKTIKVLLEYADKMFTYVFVLEMLLKWVAYGFKKYFTNAWCWLDFLIVDVSLVSLVANTLGFAEMGPIKSLRTLRAL TFI IFMILLSSGALAFEDIYLEERKTIKVLLEYADKMFTYVFVLEMLLKWVAYGFKKYFTNAWCWLDFLIVDVSLVSLVANTLGFAEMGPIKSLRTLRAL
$-1 I I S 1$ RPLRALSRFEGMRVVNALVGAIPS IMNVLLVCLIFWLIFSIMGVNLFAGKYHYCFNETSEIR-FEIDIVNNKTDCEKLMEGNSTEIRWKNVKINFDNVG RPLRALSRFEGMRVVNALLGAIPSIMNVLLVCLIFWLIF SIMGVNLFAGKFYHCVNTTTGDT-FEITEVNNHSDCLKLIERNETA-RWKNVKVNFDNVG RPLRALSRFEGMRVVVALLGAIPS IMNVLLVCLIFWLIF SIMGVNL FAGKFYHCINYTTGEM-FDVSVVNNYSECQALIESNOTA-RWKNVKVNFDNVG RPLRALSRFEGMRVVVNALVGAI PS IMNVLLVCLIFWLIF IMGVNLFAGKFYHCVNTTTTGNM-FEIKEVNNFSDCQAL---GKQA-RWKNVKVNFDNVG RPLRALSRFEGMRVVVNALLGAIPS IMNVLLVCLIFWLIFSIMGVNLFAGKFYYCVNTTTSER-FDISVVNNKSESESLMYTGO- -VRWMNVKVNYDNVG RPLRALSRFEGMRVVVNALVGAIPS IMNVLVCLIFWLIF S IMGVNL FAGKFGRCINOTEGDL PLNYT IVNNKSECESF - -NVTGEL YWTKVKVNFDNVG IIIS4 IITS5

AGYLALLQVATFKGWMDIMYAAVDSRKPDEOPDYEGN IYMY IYFVIF I IFGSFFTLNLF IGVI IDNFNOOKKKFGGODIFMTEEOKKYXNAMKKLGSKKF AGYLALLQVATFKGWMDIMYAAVDSRKPDEQPDYEGN IYMY IYFVIF I IFGSFFTLNLF IGVI IDNFNQQKKKFGGQDIFMTEEQKKYXNAMKKLGSKKF FGYLSLLQVATFKGWMD IMYAAVDSRNVELQPKYEESLYMYLYFVIF I IFGSFFTLNLF IGVI IDNFNQQKKKFGGQDIFMTEEQKKYYNAMKKLGSKKP LGYLSLLQVATFKGWMDIMYAAVDSRNVELOPKYEDNL YMYLYFVIFI IFGSFFTLNLF IGVI IDNFNQQKKKFGGODIFMTEEQKKYYNAMKKLGSKKP AGYLALLQVATFKGWMDIMYAAVDSRDVKLQPIYEENLYMYLYFVIFI IFGSF FTLNLF IGVI IDNFNQQKKKFGGQDIFMTEEQKKYYNAMKKLGSKKP

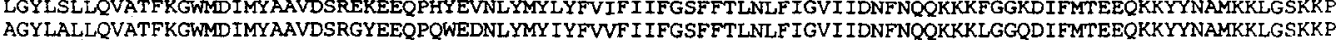
IIISSI__ IIISS2 I I IS 6

QKPIPRPLNKIOGIVEDFVTQQAFDIVIMUICLNMVTMNETDTQSKOMENILYWINLVFVIFFTCECVLKMFALRHYYFTIGWNIFDFVVILSIVGM QKPIPRPGNKFQGMVFDFVRQVFDISIMILICLNMVTMMVETDDQSDYVTSILSRINLVF IVLFTGECVLKL ISLRHYYFT IGWNIFDFVVVILS IVGM OKPIPRPANKFOGMVFDFVT KOVFDISIMIL ICINMVTMMVETDDOSOEMTNILYWINLVF IVLFTGECVLKL ISLRHYYFT IGWNI FDFVVVILS IVGM OKPIPRPANKFOGMVEDVTROVFDISIMILICLNMVTMMVETDDOSKYMTLVLSRINLVFIVLFTGEFLLKLISLRYYYFTIGWNIFDFVVVILSIVGM OKPIPRPONK IOGMYYDFVTKOVFDISIMILICLNMVTMMVETDDOSOLKVDILYNINMVF I I IFTGECVIKMFALRHYYFTIGWNIFDFVVVILS IVGL QKPIPRPLNKYQGF IFDIVTKQAFDVTIMFLICLNMVTMMVETDDQSPEKVNI LAKINL,LFVAIFTGECIVKMAALRHYYFTNSWNIFDFVVILSIVGT
IVS1

FLADI IEKYFVSPTLFRVIRLARIGRILRL IKGAKGIRTLLFALMMSLPALFNIGLLLFLVMF IFSIFGMSNFAYVKHEAGIDDMFNFETFGNSMICLFQ FLAELIEKYFV SPTLFRVIRLARIGRILRL IKGAKGIRTLL FAIMMSL PAL FNIGLLLFLVMF IYAI FGMSNFAYVKREVGIDDMFNFETFGNSMICLFO FLAELIEKYFVSPTLFRVIRLARIGRILRL IKGAKGIRTLLFALMMSL PALFNIGLLLFLVMFIYAIFGMSNFAYVKREVGIDDMFNFETFGNSMICLFO FLAEL IEKYFVSPTLFRVIRLARIGRILRL IKGAKGIRTLLFALMSLPALFNIGLLLFLVMFIYAIFGMSNFAYVRKEAGIDDMFNFETFGNSMICLFO ALSDLIOKYFV SPTLFRVIRI_ARIGRVLRL IRGAKG IRTLLFALMMSLPALFNIGLLLFLUMF IYSIFGMSNFAYVRKESGIDDMFNFETFGNSIICLFE VLSDI IQKYFFSPTLFRVIRLARIGRILRLIRGAKG IRTLLFALMSLPALFNIGLLLFLVMF IYSIFGMANFAYVKWEAGIDDMFNFQTFANSMLCLFQ ITTSAGWDGLLLPILNR-PPDCSLDKEHPGSGFKGDCGNYSVGIFFFVSYIIISFLIVVNMCI AI ILENFSVATEESADPLSEDDFETFYEIWEKFDPDA ITT'SAGWDGLLAPILNSKPPDCDPNKVNPGSSVKGDCGNPSVGIFFFVSYI I I SFLVVVNMYIAVILENFSVATEESAEPLSEDDFEMFYEVWEKFDPDA
ITTSAGWDGLLAPILNSGPPDCDPEKDHPGSSVKGDCGNPSVGIFFFVSYI I SFLVVVNMY I AVILENFSVATEESAEPLSEDDFEMFYEVWEKFDPDA ITTSAGWDGLLAPILNSAPPDCDPDA IHPGSSVKGDCGNPSVGIFFFVSYI IISFLVVVMMYIAVILENFSVATEESAEPLSEDDFEMFYEVWEKFDPDA ITTSAGWDGLLNPILNSGP PDCDPTLENEGTNVRGDCGNPSIGICFFCSYI I ISFIIVVNMY I I I LENFNVATEESSEPLSEDDFEMFYETWEKFDPDA ITTSAGWDGLLSPILNTGPPYCDFNLPNSNGS-RGNCGSPAVGILFFTWYI I ISFLIVVNMYIAI I LENFSVATEESTEPLSEDDFDMFYEIWEKFDPEA IVSS2 IVS6
TOFIEYCKLADFADALEHPLRVPKPNTIELIAMDLPMVSGDRIHCLDILFAFTKAVLGDSGELDILROOMEERFVASNPSKVSYEAYHTTLRRNEEEVSA TOFMEFEKLSOFAAALEPPINLPOPNKLOL IARDLPMVSGDRIHCLDILFAFRRVIGESGEMDALRIOMEERFMASNPSKVSYOPITTTLKRKOEEVSA TQFMEFEKLSQFAAALEPPLNLPQPNKLQL IAMDLPWVSGDRIHCLDILFAFTKRVLGESGEMDALRIQMEERFMASNPSKVSYQPITTTLKRKQEEVSA TQFIEFCKL SDFANALPPLLIAKPNKVQL IAMDLPMVSGDRIHCLDILFAFTKRVLGESGEMDALRIQMEERFMASNPSKVSYEPITTTLKRKOEEVSA TQFIEFCKL SDFAAALDPPLI IAKPNKVQL IAMDLPMVSGDRIHCLDILFAFTKRVLGESGEMDALRIQMEDRFMASNPSKVSYEPITTTLKRKQEEVSA TQF IDYSRLSDFVDTLQEPLKIAKPNKIKL ITLDLPMVPGKIHCLDILFALTKEVLGDSGEMDALKOTMEEKFMAANPSKVSYEPITTTLKRKQEEVCA
TOF IEYLAL SDFADALSEPLRIAKPNOISLINMD PMVSGDRIKCMDILFAFTKRVLGESGEMDALKIOMEEKFMANPSKISYEPITTTLRRKHEEVSA NGTHRDKKESTPSTASLPSYDSVTKPDKEKQQRAE- - . WVQRAYRGHLARR-----GFICRKSTKL VI IQRAYRRHLLKRTVKQASFTYNKNKLKG---GANLLVKEDMI IDRIN- - - - - ENSITEKTDLTMSTAACPPSYDRVTKPIVEKHEQ-...... IVIQRAYRRYLLKQKVKKVSSI YKKDKGKE-- -DEGTPIKEDI ITDKLN- - - - -ENSTPEKTDVT-PS'TTSPPSYDSVTKFEKEKFEY AIIQRNYRCYLLKQRLKNI SSKYDKETIKG - -RIDLPIKGDMVIDKLN- - - - - - GNSTPEKTDGS-SSTTSPPSYDSVTKPDKEKFEK--- - IKIORAYRRHLORSYKOA TVIORAFRRHLLQRSVKHASFLFROOAGGSGLSDEDAPEREGLIAYMMNGFSRR-_-_- SAPLSSSSISSTSFPPSYDSVTRATSDNL-PVRASDYSR
EGRRERAKRQKEVRESKC

- E- - - - - GKDEKAKGK

- - DKSEKEDKGKDIRESKK

- -DKPEKEI KGKEVRENQK

SSSPPQGQTVRPGVKESLV

SEDLADFPPSPDRDRESIV

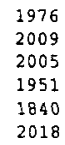

009

840

2018

- potential glycosylation site

potential protein kinase A phosphorylation site

\{ potential protein kinase $C$ phoshorylation site

Figure 2. Amino acid sequence of NaCh6 and its alignment with five other full-length rat NaCh sequences. Alignments were done using the CLUSTAL program from PCGENE (Intelligenetics). Gaps are indicated by dashes. Consensus sites for N-glycosylation in predicted extracellular domains and protein kinase $\mathrm{A}$ and $\mathrm{C}$ sites in predicted cytoplasmic domains are indicated for NaCh6. Sequences for rat brain NaCh I and II are from Noda et al. (1986); sequence for rat brain NaCh III is from Kayano et al. (1988); sequence for SkM1 is from Trimmer et al. (1989); and sequence for SkM2 is from Rogart et al. (1989) and Kallen et al. (1990). 
Table 1. Percentage of amino acid identity between NaCh6 and other rat sodium channels

\begin{tabular}{llllllllll} 
& L0 & D1 & L1 & D2 & L2 & D3 & L3 & D4 & L4 \\
\hline NaCh I & 69 & 81 & 57 & 93 & 70 & 84 & 94 & 83 & 57 \\
NaCh II & 67 & 81 & 53 & 93 & 65 & 84 & 94 & 85 & 67 \\
NaCh III & 68 & 82 & 57 & 94 & 60 & 86 & 94 & 83 & 65 \\
SkM1 & 57 & 81 & 46 & 90 & 40 & 83 & 93 & 81 & 54 \\
SkM2 & 54 & 74 & 41 & 80 & 31 & 80 & 91 & 78 & 60 \\
Na-G & - & - & - & - & - & - & - & 50 & 45
\end{tabular}

Amino acid alignments were done using the CLUSTAL program from Intellige netics. Gaps put in the sequences for alignment purposes are not counted as mismatches. DI-D4 are the membrane-spanning regions depicted in Figure 2 $\mathrm{LO}$ is the $\mathrm{NH}_{2}$ terminus, and $\mathrm{L} 4$, the $\mathrm{COOH}$ terminus. L1, L2, and L3 are the interdomain regions believed to be cytoplasmic.

(Table 1). The large cytoplasmic domains are more divergent, with about $30-70 \%$ identity between $\mathrm{NaCh} 6$ and the brain or muscle channels, and a comparison of these cytoplasmic regions shows that NaCh6 is more similar to brain than to muscle NaChs.

\section{Northern analysis}

Northern analysis was performed on RNA isolated from different tissues (Fig. 3). A riboprobe for the 3' untranslated region was used to detect NaCh6 mRNA. Two bands, a prominent one at $9.5 \mathrm{~kb}$ and a fainter one at $10.4 \mathrm{~kb}$, were detected in brain, cerebellum, and spinal cord. No transcripts were detected in kidney, lung, uterus, and skeletal and cardiac muscle. The reason for the two different transcript sizes is not known. One possibility is that the length of the $3^{\prime}$ untranslated region is variable, due either to the use of different polyadenylation signal sites, as suggested for $\mathrm{NaCh}$ III (Suzuki et al., 1988), or to alternative splicing.

\section{mRNA abundance}

We used RNase protection analysis, which is both specific and sensitive, to quantitate the abundance of NaCh6 mRNA. The abundance of NaCh6 mRNA was compared to that of NaChs I, II, and III and to alternative splicing isoforms of NaChs I and III (Schaller et al., 1992). Figure 4 shows the results of RNase protection with each of these probes to adult rat brain RNA. The relative abundances of the labeled bands in Figure 4 were quantitated by measuring the radioactive decay with a PhosphoImager. The ratios of $\mathrm{NaCh} 6: \mathrm{NaCh} \mathrm{I}: \mathrm{NaCh} \mathrm{Ia}: \mathrm{NaCh}$ II/IIa: $\mathrm{NaCh}$ III:NaCh IIIa: NaCh IIIb were 1:0.14:0.83:0.75:0.17:0.07:0.02. Thus, the RNA protected by $\mathrm{NaCh} 6$ was as abundant as the RNA of any of the isoforms of NaChs I, II, or III. Given this abundance, it is surprising that this channel was not cloned earlier.

\section{Glial expression of $\mathrm{NaCh} 6$}

None of the experiments described above indicated what cell types in the nervous system express NaCh6. The ability to amplify and clone NaCh6 cDNA from RNA of primary cultures of cortical astrocytes suggested that this channel is expressed in astrocytes. However, PCR is extremely sensitive, and since these cultures are not purely of one cell type (Yarowsky and Krueger, 1989), we performed in situ hybridization in combination with GFAP immunocytochemistry to confirm that NaCh6 mRNA was expressed in cultured astrocytes. The specificity of the in situ hybridization results was assured by the use of synthetic oligon-

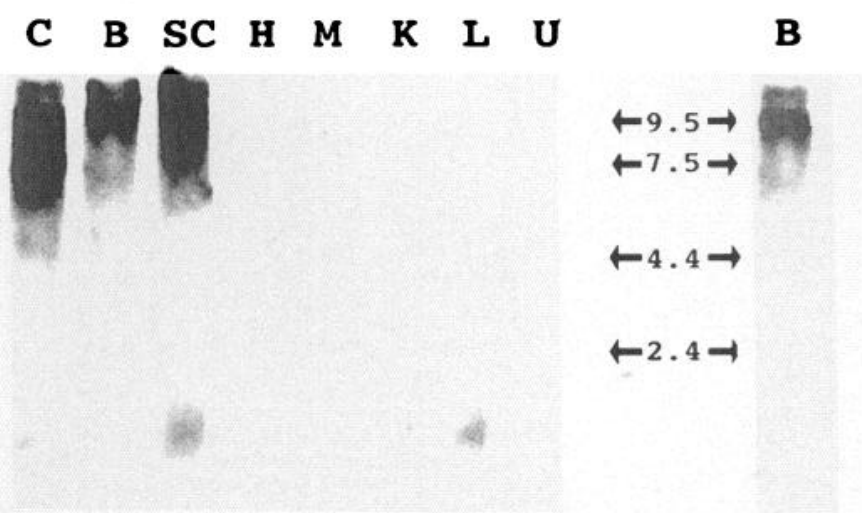

Figure 3. Northern blot of RNAs. Cerebellum $(C)$, brain $(B)$, spinal cord $(S C)$, heart $(H)$, skeletal muscle $(M)$, kidney $(K)$, lung $(L)$, and uterus $(U)$. Molecular size markers (in kb) are indicated. Two bands, 9.5 and $10.4 \mathrm{~kb}$, were observed only in nervous system tissue. The lanes to the left of the marker lane were overexposed to show the lack of NaCh6 mRNA in non-nervous tissues. The lane to the right of the marker, a lighter exposure of brain $(B)$ RNA, shows that the most abundant NaCh6 transcript in brain is $9.5 \mathrm{~kb}$.

ucleotides, rather than a larger cDNA clone, as hybridization probes, since over the length of the coding region NaCh6 shows $65-70 \%$ identity with the previously cloned rat brain cDNAs. Two antisense oligonucleotide probes specific for $\mathrm{NaCh} 6$ were synthesized, one for a cytoplasmic region (oligo 6A2) and the other for an extracellular region (oligo 6A1). As a control, one sense oligonucleotide probe was synthesized. The oligonucleo-

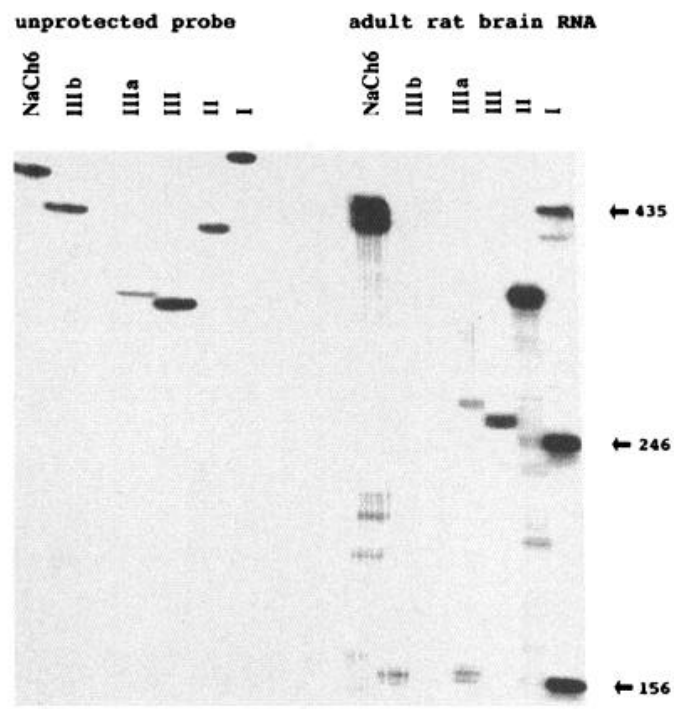

Figure 4. RNase protection to quantitate $\mathrm{NaCh}$ isoforms. Riboprobes were made that were specific for NaChs I, II, III, 6 and several splicing isoforms (Ia, IIIa, and IIIb) that we characterized previously (Schaller et al., 1992). These probes, in 100-fold excess, were hybridized to RNA from brain, and the protected RNAs were electrophoresed on a polyacrylamide gel and analyzed by a PhosphoImager that quantitates the radioactivity in the gel. The right half of the image shows the protected mRNA fragments. The left half shows an aliquot of the unprotected probes. The first lane on the right has three heavily labeled bands (arrows); the top band ( $435 \mathrm{nt}$ ) is $\mathrm{NaCh} \mathrm{I} \mathrm{mRNA} \mathrm{and} \mathrm{the} \mathrm{two} \mathrm{lower} \mathrm{bands}$ are protected fragments of $\mathrm{NaCh}$ Ia mRNA, which has an 11 amino acid deletion relative to Ia and causes the $\mathrm{NaCh}$ I probe to be cut into two pieces (156 and $246 \mathrm{nt}$ ). The signal from isoform IIIa is nine nucleotides longer than III. The signal from isoform IIIb (96 nucleotides longer than III) was too weak to be visible at this exposure. 

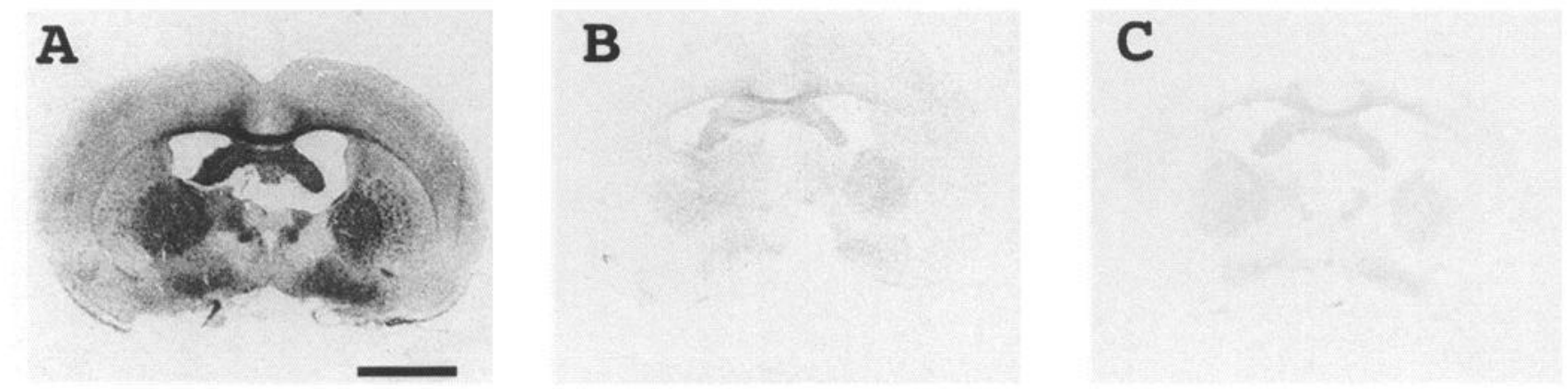

Figure 5. In situ hybridization controls. Film autoradiogram of coronal sections of an adult rat brain. A, Antisense oligonucleotide. Labeling of the globus pallidus, hippocampal commissure, corpus callosum, and cortex. $B$, Sense oligonucleotide. $C$, Competition of ${ }^{35} S$-labeled antisense oligonucleotide with a 50 -fold excess of unlabeled antisense oligomer. Scale bar, $3 \mathrm{~mm}$.

tide probes for $\mathrm{NaCh} 6$ were designed by choosing regions where the number of mismatches between the oligonucleotide and the other isoforms was maximized (see Materials and Methods). Three results were consistent with the probes being specific for NaCh6. First, in situ hybridization with these two different antisense probes showed strong labeling (Fig. 5A) and identical patterns of expression of NaCh6. In situ hybridization showed little labeling with the sense probe (Fig. $5 B$ ) or when excess unlabeled antisense probe was added to compete with the labeled antisense probe (Fig. 5C). Second, oligonucleotide 6Al was used to screen a rat brain library (described above), and all of the 35 clones isolated were NaCh6. Third, oligonucleotide 6A2 was used with a degenerate generic $\mathrm{NaCh}$ primer for RT-PCR amplification. Sequencing of individual partial cDNA clones (five clones) from the RT-PCR showed that all these cDNAs were NaCh6.

Primary cultures (2-3 weeks old) of neonatal rat astrocytes were fixed and hybridized with NaCh6 sense or antisense oligonucleotide probes that were end labeled with ${ }^{35} \mathrm{~S}-\mathrm{dATP}$. Each of the antisense probes gave the same result: virtually all cells were labeled (Fig. 6A,B). There was no specific labeling with the sense probe. Immunocytochemical labeling with anti-GFAP antibody showed that over $95 \%$ of the cells in these cultures were GFAP positive (Fig. 6C). Thus, the in situ hybridization demonstrated that cortical astrocytes (GFAP positive) in culture express NaCh6 mRNA.

In addition to the PCR amplification from cultures of astrocytes, two experiments further indicated that astrocytes express NaCh6. When the CNS is injured, astrocytes respond by proliferating and forming scar tissue. The scar is created by the generation of astrocyte processes that are especially abundant in glial intermediate filaments composed of GFAP. Cryostat sections of a rat brain that had been lesioned (by insertion of a needle into the cortex and striatum) $10 \mathrm{~d}$ prior to death were incubated with the NaCh6 probe. The cells most heavily labeled were cells on the border of the lesion (Fig. 6D), and these cells had processes that were intensely labeled by the antibody against GFAP. The second line of evidence came from an immortal cell line (A7) generated from the rat CNS that has many properties of astrocytes (Geller and Dubois-Dalcq, 1988). These cells were labeled by an NaCh6 antisense probe but not by the sense probe (Fig. 6E,F).

It was possible that astrocytes in culture expressed NaCh6 as a consequence of the isolation and culture conditions. To test for in vivo expression in glia in normal, adult rats, we performed in situ hybridization on sections of the brain and spinal cord
(Fig. 7). Due to the intimate intermingling of neurons and glia in most regions of the CNS, it was difficult at the light microscopic level to determine unequivocally if glial cells were labeled. Therefore, white matter tracts were examined for labeled cells.

Spinal cord sections allowed clear identification of labeled glia in the white matter. Cells that were associated with GFAPpositive processes in the white matter were labeled (Fig. 7A, $B$; small arrows illustrate a few of these). It is unlikely that these labeled cells were oligodendrocytes because oligodendrocytes are GFAP negative, are more abundant than the labeled cells we observe, and have never been found to express $\mathrm{Na}$ currents in electrophysiological recordings. These cells are also not likely to be neurons because the occurrence of neurons in spinal cord white matter is rare (Donald, 1953). Thus, we conclude that astrocytes in white matter of the spinal cord express NaCh6.

In situ hybridization indicated that Schwann cells express NaCh6. Heavy, relatively uniform labeling of dorsal roots was observed (Fig. 7A). Dorsal root labeling stopped abruptly at the zone of Obersteiner-Redlich (large arrow in Fig. 7A), the location at which glial cells change from peripheral (Schwann cells) to central (oligodendrocytes). The GFAP labeling also changed at this transition zone; it became weak or nonexistent distal to the zone. Since axons do not contain mRNA, labeling with the NaCh6 probe is consistent with reports that Schwann cells express NaChs while oligodendrocytes do not.

Examination of white matter tracts in the brain was less clear cut than in the spinal cord. Some labeling was evident in cerebellar white matter (Fig. $7 E$ ). However, there was little labeling of the optic nerve (Fig. $7 \mathrm{C}$ ) compared to the adjacent region of the hypothalamus above the chiasm. There was also some labeling of two commissural tracts: the corpus callosum and the hippocampal commissure (Fig. 5A). Thus, it is possible that expression of $\mathrm{NaCh} 6$ is heterogeneous in astrocytes (see Discussion).

\section{Neuronal expression of $\mathrm{NaCh} 6$}

The distribution of NaCh6 was widespread in the spinal cord and brain. Examples of neuronal labeling in the CNS are presented (Fig. 7). Many cells in the gray matter of the spinal cord were labeled, but the type of cell often could not be determined. However, some of the largest neurons were clearly labeled. Motor neurons, identified by their size and position, showed intense labeling (Fig. 7B), as did preganglionic sympathetic neurons in the intermediolateral cell column (not shown). Primary motor 

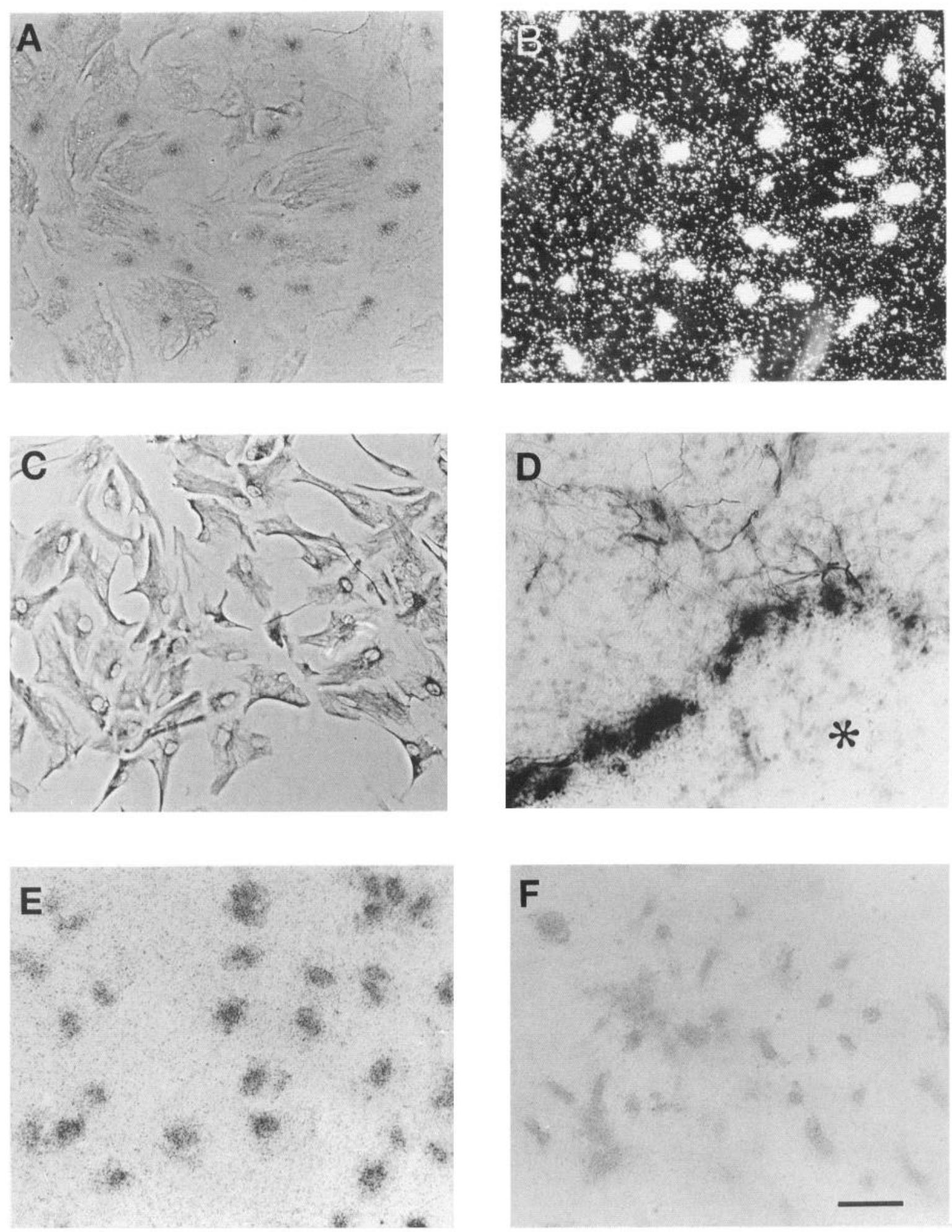

Figure 6. Astrocyte labeling by in situ hybridization of oligonucleotide probes specific for NaCh6. A-C, Primary cultures of neonatal rat cortical astrocytes. Bright-field $(A)$ and dark-field $(B)$ photomicrographs of a culture labeled with NaCh6 antisense probe. Virtually every cell in the culture hybridized to the antisense probe. $C$. Immunohistochemical labeling of a parallel culture of astrocytes with antibodies against GFAP; essentially all cells were labeled. $D$, Combined in situ hybridization and GFAP immunohistochemistry on a section of rat brain lesioned $10 \mathrm{~d}$ earlier; astrocytes on the border of the lesion are heavily labeled. Cavity created by lesion is indicated by an asterisk. $E$ and $F$, Cultures of an astrocyte-like cell line (A7) hybridized with antisense $(E)$ or sense $(F)$ oligonucleotide probes. Scale bar: $65 \mu \mathrm{m}$ for $A$ and $B, 100 \mu \mathrm{m}$ for $C$, and $50 \mu \mathrm{m}$ for $D-F$. 

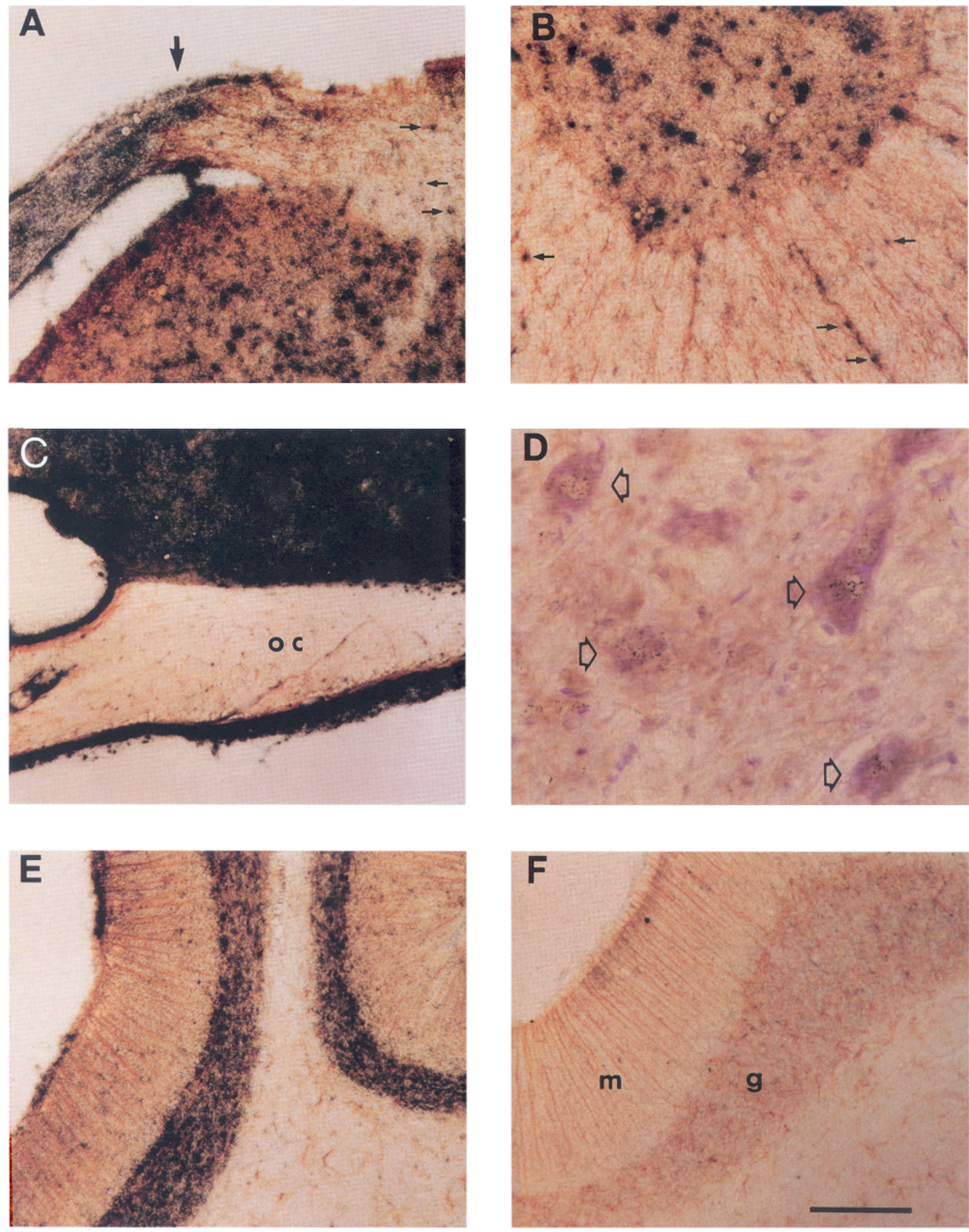

Figure 7. GFAP immunocytochemistry combined with in situ hybridization for NaCh6. A, Dorsal horn and dorsal root of the spinal cord. Cells in the gray matter were heavily labeled. Cells in the white matter were also labeled (small arrows illustrate a few examples). Uniform labeling occurred over the peripheral portion of the dorsal root; this labeling stopped at the zone of Obersteiner-Redlich (large arrow) where GFAP labeling became intense centrally and where myelin formation changed from Schwann cells to oligodendrocytes. $B$, Ventral horn and ventral funiculus of the spinal cord. Motor neurons were heavily labeled. GFAP-positive cells in the white matter were also labeled (some of these are indicated with small arrows). $C$, Optic chiasm. Intense labeling occurred dorsal to the chiasm but the optic nerve and optic chiasm (oc) exhibited little labeling (parasagittal section; rostral is to the left). $D$, Facial nucleus of the brainstem counterstained with cresyl violet. Silver grains are located over motor neurons (open arrowheads). E, Cerebellum. Antisense oligonucleotide hybridized strongly to the granule cell layer, moderately and uniformly to the molecular layer, and weakly to the white matter tracts entering and leaving the cerebellar cortex. Some cells in the molecular layer were labeled. GFAP labeling of Bergmann glia was evident in the molecular layer. $F$, Cerebellum. Hybridization of a sense probe was at or near background in the granule cell $(g)$ and molecular $(m)$ layers. Scale bar: $200 \mu \mathrm{m}$ for $A, B, E$, and $F, 500 \mu \mathrm{m}$ for $C$, and $50 \mu \mathrm{m}$ for $D$. 
neurons in the brainstem, for example, in the facial nucleus (Fig. $7 D)$, were labeled.

In the cerebellum Purkinje cells were labeled, and the cerebellar granule cell layer was heavily labeled (Fig. 7E). Much of this labeling was in granule cells since identification of astrocytes by anti-GFAP antibodies in sections hybridized with the sense probe (Fig. $7 F$ ) showed that GFAP-positive astrocytes were not abundant enough to account for all of the labeling in the granule cell layer. A few isolated cells in the molecular layer were labeled. Neurons in the deep cerebellar nuclei were also labeled (not shown). We conclude that $\mathrm{NaCh} 6 \mathrm{mRNA}$ is present in many types of neurons in the cerebellum.

In the hippocampus, granule cells of the dentate gyrus and pyramidal cells were labeled (not shown). There did not appear to be any obvious difference in labeling of CA1 versus CA3 pyramidal cells, or in granule cell labeling within the dentate gyrus.

There was no obvious rostral-caudal gradient of NaCh6 mRNA from in situ hybridization. This is in contrast to what has been found for the distribution of NaChs I and II; NaCh I is most abundant in the caudal CNS and the opposite is true for $\mathrm{NaCh}$ II (Beckh et al., 1989). NaCh III, unlike NaCh6, is expressed at low levels in the adult brain, with little or no expression in the cerebellum (Furuyama et al., 1993; Black et al., 1994). Thus, NaCh6 not only is broadly expressed throughout the CNS hut also has a distribution different from that of the other brain NaChs.

\section{Discussion}

The two most significant aspects revealed by isolation of NaCh6 are, first, that it is one of the most abundant NaChs in the nervous system at the RNA level and, second, that it is expressed in both neurons and glia. Beckh et al. $(1989,1990)$ showed with Northern blot analysis that NaChs I, II, and III did not account for all the $\mathrm{NaCh}$ mRNA in the rat nervous system. The signal they obtained using a generic cDNA probe was larger than the combined signal for probes specific for $\mathrm{NaChs} \mathrm{1,} \mathrm{Il,} \mathrm{and} \mathrm{III,} \mathrm{suggesting} \mathrm{the} \mathrm{existence} \mathrm{of} \mathrm{one} \mathrm{or} \mathrm{more}$ novel NaCh mRNAs. Using RT-PCR, NaCh6 was shown to be in many of these tissues, including retina and dorsal root ganglia. RNase protection analysis (Fig. 4) showed that the amount of NaCh6 mRNA was at least as abundant as that of rat brain NaChs I, II, and III, including the isoforms generated by alternative splicing. In situ hybridization with a probe specific for NaCh6 (Fig. 7) was consistent with the RNase protection; many areas of the brain and spinal cord were heavily labeled. DRG neurons were also labeled (Schaller, Krzemien, and Caldwell, unpublished observations). Areas of the CNS expressing NaCh6 can be compared to areas labeled with in situ hybridization using probes specific for NaChs I, II, and III (Brysch et al., 1991; Furuyama et al., 1993; Black et al., 1994a). There was overlap in distribution, but none of the other channels had the same distribution as NaCh6. Thus, we conclude that NaCh6 is an abundant $\mathrm{NaCh}$ in the adult rat CNS and has a broad distribution that is different from the distributions of the other brain NaChs.

Schwann cells and astrocytes express voltage-gated sodium channels (Barres et al., 1990; Ritchie, 1992; Sontheimer, 1994). The specific $\mathrm{NaCh}$ isoforms expressed in glia are beginning to be characterized. NaChs I, II, and III have been shown to be expressed in glia (Black et al., 1994; Oh et al., 1994b). In addition, a partial NaCh cDNA (designated $\mathrm{Na}-\mathrm{G}$ ) expressed in glia has been reported (Gautron et al., 1992). The Na-G transcript is very different from NaCh6 in both sequence and distribution. From amino acid sequence comparisons, all of the full-length $\mathrm{NaChs}$ in Figure 2, including $\mathrm{NaCh} 6$, belong to one family. A second $\mathrm{NaCh}$ family is formed by $\mathrm{Na}-\mathrm{G}$ and $\mathrm{hNa}_{\mathrm{v}} 2.1$ (a human cDNA obtained from cardiac muscle; George et al,, 1992); amino acid similarities between cDNAs of these two families are much lower (about 50-60\% for transmembranc regions and $5-45 \%$ for the large cytoplasmic regions) than those within a family (Table 1). The tissue distribution of $\mathrm{Na}-\mathrm{G}$ is also very different from that of $\mathrm{NaCh} 6 . \mathrm{Na}-\mathrm{G}$ is expressed in uterus, lung, and cardiac muscle, while NaCh6 was not detected in these tissues (Fig. 3). In the brain and adult spinal cord there is a low abundance of Na-G (Gautron et al., 1992), in contrast to the high abundance of NaCh6 (Fig. 4). Thus, although both $\mathrm{NaCh} 6$ and $\mathrm{Na}-\mathrm{G}$ are expressed in glial cells, the comparisons of tissue abundance and distribution suggest that they play different roles in glia of the CNS.

The strong amino acid identity in the transmembrane regions (Table 1, Fig. 2) leaves no doubt that this novel cDNA encodes a sodium channel. All four S4 transmembrane segments that are thought to function as the voltage sensor are completely conserved (i.e., amino acids of $\mathrm{NaCh} 6$ are identical to those of cither brain or muscle), and the short cytoplasmic domain between transmembrane domains III and IV, which is crucial for inactivation, is almost totally conserved ( 52 of 53 amino acids identical to either brain or muscle sequences). Two amino acids (K1409 and A1701) that distinguish between $\mathrm{Na}$ and $\mathrm{Ca}$ permeability (Heinemann et al., 1992) are also consistent with the identification of $\mathrm{NaCh} 6$ as a sodium channel. The major differences between $\mathrm{NaCh}$ sequences lie in the intra- and extracellular domains (Table 1). The size of these domains in $\mathrm{NaCh} 6$ is closer to brain than muscle NaChs. These domains contain potential sites for post-translational modifications, for example, by phosphorylation or glycosylation (Fig. 2). Functional expression will be necessary to determine the effects of phosphorylation or glycosylation, as well as the voltage dependence, kinetic properties, and toxin sensitivity that are unique to NaCh6.

$\mathrm{NaChs}$ are essential for electrical excitability in the nervous system. The classic example of this is the conduction of action potentials in myelinated and nonmyelinated axons. However, there is increasing evidence that NaChs are employed for more subtle, subthreshold, signal processing in neurons. NaChs are found in the dendrites of cerebellar Purkinje cells (Regehr et al., 1992) and of pyramidal cells in both the hippocampus ( $R e-$ gehr et al., 1993) and cortex (Huguenard et al., 1989; Stuart and Sakmann, 1994). These NaChs are capable of generating dendritic action potentials, and their density and distribution in dendrites will modify synaptic responses. In order to understand the effect of NaChs on synaptic integration, it is essential to know for each class of neuron what $\mathrm{NaCh}$ isoforms are present and the properties and distribution of each isoform.

All the NaChs isolated from nervous tissue, including $\mathrm{NaCh} 6$, have been shown to be expressed in glia. Since astrocytes are biochemically and morphologically heterogeneous, it will be important to determine the isoforms expressed in each astrocyte subtype. In addition, there is evidence that $\mathrm{NaChs}$ are segregated to different regions of the astrocyte, for example, in the processes (Barres et al., 1990) and in apposition to nodes of Ranvier (Black et al., 1989). Thus, the distribution of NaChs in glia may be as complex as that in neurons. Knowledge of 
the biophysical propertics and subcellular localization of each $\mathrm{NaCh}$ isoform will be essential for determining why glia express voltage-gated NaChs. Antibodies that are specific for NaCh6 will be valuable tools for determining the subcellular distribution in both neurons and glia.

GenBank accession number. The accession number for the NaCh6 sequence is L39018.

\section{References}

Barres BA, Chun LL, Corey DP (1990) Ion channels in vertebrate glia. Annu Rev Neurosci 13:441-474.

Beckh S (1990) Differential expression of sodium channel mRNAs in rat peripheral nervous system and innervated tissues. FEBS Lett 262:317-322.

Beckh S, Noda M, Lubbert H, Numa S (1989) Differential regulation of three sodium channel messenger RNAs in the rat central nervous system during development. EMBO J 8:3611-3616.

Black JA, Waxman SG, Friedman B, Elmer LW, Angelides KJ (1989) Sodium channels in astrocytes of rat optic nerve in situ: immunoelectron microscopic studies. Glia 2:353-369.

Black JA, Yokoyama S, Higashida H, Ransom BR, Waxman SG (1994a) Sodium channel mRNAs I, II and III in the CNS: cellspecific expression. Brain Res Mol Brain Res 22:275-289.

Black JA, Yokoyama S, Waxman SG, Oh Y, Zur KB, Sontheimer H, Higashida H, Ransom BR (1994b) Sodium channel mRNAs in cultured spinal cord astrocytes: in situ hybridization in identified cell types. Mol Brain Res 23:235-245.

Brysch W, Creutzfeldt OW, Lüno K, Schlingensiepen R, Schlingensiepen K-H (1991) Regional and temporal expression of sodium channel messenger RNAs in the rat brain during development. Exp Brain Res 86:562-567.

Chomczynski P, Sacchi N (1987) Single-step method of RNA isolation by acid guanidinium thiocyanate-phenol-chloroform extraction. Anal Biochem 162:156-159.

D'Arcangelo G, Paradiso K, Shepard D, Brehm P, Halegoua S, Mandel G (1993) Neuronal growth factor regulation of two different sodium channel types through distinct signal transduction pathways. J Cell Biol 122:915-921.

Dascal N, Lotan I (1991) Activation of protein kinase C alters voltage dependence of a $\mathrm{Na}^{+}$channel. Ncuron 6:165-175.

Donald D (1953) On the incidence and locations of nerve cells in the spinal white matter of two species of primates, human and the cynomolgus monkey. J Comp Neurol 99:103-115.

Furuyama T, Morita Y, Inagaki S, Takagi H (1993) Distribution of I, II and III subtypes of voltage-sensitive $\mathrm{Na}^{+}$channel mRNA in the rat brain. Brain Res Mol Brain Res 17:169-173.

Gautron S, Dos Santos G, Pinto-Henrique D, Koulakoff A, Gros F, Berwald-Netter Y (1992) The glial voltage-gated sodium channel: cell- and tissue-specific mRNA expression. Proc Natl Acad Sci USA 89:7272-7276.

Geller HM, Dubois-Dalcq M (1988) Antigenic and functional characterization of a rat central nervous system-derived cell line immortalized by a retroviral vector. J Cell Biol 107:1977-1986.

George AL Jr, Knittle TJ, Tankun MM (1992) Molecular cloning of an atypical voltage-gated sodium channel expressed in human heart and uterus: evidence for a distinct gene family. Proc Natl Acad Sci USA 89:4893-4897.

Gershon E, Weigl L, Lotan I, Schreibmayer W, Dascal N (1992) Protein kinase A reduces voltage-dependent $\mathrm{Na}^{+}$current in Xenopus oocytes. J Neurosci 12:3743-3752.

Gustafson TA, Clevinger EC, O'Neill TJ, Yarowsky PJ, Krueger BK (1993) Mutually exclusive exon splicing of type III brain sodium channel alpha subunit RNA generates developmentally regulated isoforms in rat brain. J Biol Chem 268:18648-18653.

Heinemann SH, Terlau H, Stuhmer W, Imoto K, Numa S (1992) Calcium channel characteristics conferred on the sodium channel by single mutations. Nature 356:441-443.

Huguenard JR, Hamill OP, Prince DA (1989) Sodium channels in dendrites of rat cortical pyramidal neurons. Proc Natl Acad Sci USA 86:2473-2477.

Isom LL, De Jongh KS, Patton DE, Reber BF, Offord J, Charbonneau H, Walsh K, Goldin AL, Catterall WA (1992) Primary structure and functional expression of the beta 1 subunit of the rat brain sodium channel. Science 256:839-842.

Isom LL, DeJongh KS, Catterall WA (1994) Auxiliary subunits of voltage-gated ion channels. Neuron 12:1183-1194.

Kallen RG, Sheng ZH, Yang J, Chen LQ, Rogart RB, Barchi RL (1990) Primary structure and expression of a sodium channel characteristic of denervated and immature rat skeletal muscle. Neuron $4: 233-242$.

Kayano T, Noda M, Flockerzi V, Takahashi H, Numa S (1988) Primary structure of rat brain sodium channel III deduced from the cDNA sequence. FEBS Lett 228:187-194.

Li M, West JW, Lai Y, Scheuer T, Catterall WA (1992) Functional modulation of brain sodium channels by cAMP-dependent phosphorylation. Neuron 8:1151-1159.

Lotan I, Dascal N, Naor Z, Boton R (1990) Modulation of vertebrate brain $\mathrm{Na}^{+}$and $\mathrm{K}^{+}$channels by subtypes of protein kinase C. FEBS Lett 267:25-28.

Mahalik TJ, Carrier A, Owens GP, Clayton G (1992) The expression of GAP43 mRNA during the late embryonic and early postnatal development of the CNS of the rat: an in situ hybridization study. Brain Res Dev Brain Res 67:75-83.

Noda M, Ikeda T, Kayano T, Suzuki H, Takeshima H, Kurasaki M, Takahashi H, Numa S (1986) Existence of distinct sodium channel messenger RNAs in rat brain. Nature 320:188-192.

Oh Y, Black JA, Waxman SG (1994) The expression of rat brain voltage-sensitive $\mathrm{Na}^{+}$channel mRNAs in astrocytes. Mol Brain Res 23:57-65.

Recio-Pinto E, Thornhill WB, Duch DS, Levinson SR, Urban BW (1990) Neuraminidase treatment modifies the function of electroplax sodium channels in planar lipid bilayers. Neuron 5:675-684.

Regehr WG, Konnerth A, Armstrong CM (1992) Sodium action potentials in the dendrites of cerebellar Purkinje cells. Proc Natl Acad Sci USA 89:5492-5496.

Rcgehr W, Kehoe J, Ascher P, Armstrong C (1993) Synaptically triggered action potentials in dendrites. Neuron 11:145-151.

Ritchie JM (1992) Voltage-gated ion channels in Schwann cells and glia. Trends Neurosci 15:345-351.

Rogart RB, Cribbs LL, Muglia LK, Kephart DD, Kaiser MW (1989) Molecular cloning of a putative tetrodotoxin-resistant rat heart $\mathrm{Na}^{+}$ channel isoform. Proc Natl Acad Sci USA 86:8170-8174.

Sambrook J, Fritsch EF, Maniatis T (1989) Molecular cloning: a laboratory manual. Cold Spring Harbor, NY: Cold Spring Harbor Laboratory.

Sarao R, Gupta SK, Auld VJ, Dunn RJ (1991) Developmentally regulated alternative RNA splicing of rat brain sodium channel inRNAs. Nucleic Acids Res 19:5673-5679.

Schaller KL, Krzemien DM, McKenna NM, Caldwell JH (1992) Alternatively spliced sodium channel transcripts in brain and muscle. J Neurosci 12:1370-1381.

Schreibmayer W, Dascal N, Lotan I, Wallner M, Weigl L (1991) Molecular mechanism of protein kinase $\mathrm{C}$ modulation of sodium channel alpha-subunits expressed in Xenopus oocytes. FEBS Lett 291: 341-344.

Sills MN, Xu YC, Baracchini E, Goodman RH, Cooperman SS, Mandel G, Chien KR (1989) Expression of diverse $\mathrm{Na}^{+}$channel messenger RNAs in rat myocardium. Evidence for a cardiac-specific $\mathrm{Na}^{+}$channel. J Clin Invest 84:331-336.

Sontheimer H (1994) Voltage-dependent ion channels in glial cells. Glia 11:156-172.

Stuart GJ, Sakmann B (1994) Active propagation of somatic action potentials into neocortical pyramidal cell dendrites. Nature 367:6972.

Suzuki H, Beckh S, Kubo H, Yahagi N, Ishida H, Kayano T, Noda $M$, Numa $S$ (1988) Functional expression of cloned cDNA encod ing sodium channel III. FEBS Lett 228:195-200.

Thackeray JR, Ganetsky B (1994) Developmentally regulated alternative splicing generates a complex array of Drosophila para sodium channel isoforms. J Neurosci 14:2569-2578.

Trimmer JS, Cooperman SS, Tomiko SA, Zhou JY, Crean SM, Boyle MB, Kallen RG, Sheng ZH, Barchi RL, Sigworth FJ, Goodman RH, Agnew WS, Mandel G (1989) Primary structure and functional expression of a mammalian skeletal muscle sodium channel. Neuron 3:33-49.

Trimmer JS, Cooperman SS, Agnew WS, Mandel G (1990) Regula- 
tion of muscle sodium channel transcripts during development and in response to denervation. Dev Biol 142:360-367.

West JW, Numann R, Murphy BJ, Scheuer T, Catterall WA (1992) Phosphorylation of a conserved protein kinase $\mathrm{C}$ site is required for modulation of $\mathrm{Na}^{+}$currents in transfected Chinese hamster ovary cells. Biophys J 62:31-33.

Westenbroek RE, Merrick DK, Catterall WA (1989) Differential subcellular localization of the RI and RII $\mathrm{Na}^{+}$channel subtypes in central neurons. Neuron 3:695-704.
Wollner DA, Scheinman R, Catterall WA (1988) Sodium channel expression and assembly during development of retinal ganglion cells. Neuron 1:727-737.

Yarowsky PJ, Krucger BK (1989) Development of saxitoxin-sensitive and insensitive sodium channels in cultured neonatal rat astrocytes. J Neurosci 9:1055-1061.

Yarowsky PJ, Krueger BK, Olson CE, Clevinger EC, Koos RD (1991) Brain and heart sodium channel subtype mRNA expression in rat cerebral cortex. Proc Natl Acad Sci USA 88:9453-9457. 